\title{
Editorial
}

\section{Health Systems in Post-Covid-19 Era: Strengthening Primary Care and District Hospitals}

\author{
Rajeev Gupta \\ Editor, RUHS Journal of Health Sciences; Chair, Academic and Research Development Unit, \\ Rajasthan University of Health Sciences, Jaipur, Rajasthan, India
}

Covid-19 continues to create massive burden on health system in India. ${ }^{1}$ Public health systems are stressed because the only strategy that is currently available for prevention of the disease are lockdowns, isolation of suspected and confirmed cases, and personal protection measures. Preventive vaccine development is still a work-in-progress and although more than 100 vaccines are being evaluated only a select few have reached phase 2 and only 1 is in phase 3 (Table 1). ${ }^{2}$ Translation of these vaccines into clinical practice or general use is some months away. Clinicians are stressed because of absence of any evidencebased treatment strategy for covid-19 patients. ${ }^{3}$ Results of observational data and clinical trials are controversial and no study has yet shown clear benefit. ${ }^{3}$ Hospitals are stressed because of lack of adequate facilities in terms of manpower, space constraints, and equipment to deal with complications of the disease. All these factors have not only been reported from India but are being observed all over the globe. ${ }^{4}$

A major public health strategy that has been shown to be beneficial in prevention of spread of covid-19 is widespread application of non-pharmaceutical interventions. These measures include universal masking, frequent hand washing and hand-hygiene, keeping surfaces clean, eye protection, and physical distancing. Studies have shown the benefits of this approach in prevention of covid19. ${ }^{5}$ While useful, personal protection measures are often cumbersome and require a high level of public awareness for it to be sustainable. The second strategy is universal and/or targeted tracing, testing for the virus, isolation of suspected individuals, and quarantine. ${ }^{6}$ This involves diagnosis of covid-19 using detection of the virus in oral or nasopharyngeal swabs using RT-PCR technology and is expensive. Stringent lockdowns to isolate whole populations to combat the virus have been used as public health strategy in many countries including India. However, prolonged lockdowns is not viable on the long term. ${ }^{7}$

\section{Resilient health systems}

Disease outbreaks and health emergencies can lead to breaking down of health systems especially fragile systems. This is widely prevalent in most developing countries. Health system has to rise to challenges posed by the epidemic and I believe that strengthening of health systems is the only viable alternative to deal not only with the current covid-19 epidemic but also to deal with epidemics of communicable and non-communicable

Table 1: Important Covid-19 vaccines in clinical trials (Mullard)

\begin{tabular}{lll}
\hline Properties & Developer & Development status \\
\hline mRNA vaccine & Moderna, NIAID & Phase 2 \\
mRNA vaccine & BioNTech, Pfizer & Phase $1-2$ \\
DNA vaccine & Inovio Pharmaceuticals 1 \\
Adenovirus vaccine & Oxford University, AstraZeneca & Phase 2b/3 \\
Adenovirus vaccine & CanSinoBiologicals & Phase 2 \\
Inactivated virus & Wuhan Institute of Biological Products, Sinopharm & Phase $1-2$ \\
Inactivated virus & Beijing Institute of Biological Products, Sinopharm Phase $1-2$ & Phase 1-2 \\
Inactivated virus and adjuvant & Sinovac & Phase 1 \\
Inactivated virus & Institute of Medical Biology, Chinese Academy of & Phase 1-2 \\
& Medical Sciences & \\
Protein subunit & Novavax & \\
\hline
\end{tabular}


Table 2: Suggested strategies for creation of resilient health systems (Durski et al) ${ }^{8}$

\begin{tabular}{|c|c|}
\hline & Strategy \\
\hline 1. & Include health system experts from the onset of emergency response. \\
\hline 2. & $\begin{array}{l}\text { Ensure that response teams are multidisciplinary and composed of project managers, data analysts, engineers, and experts in } \\
\text { health systems and applied system methodologies. }\end{array}$ \\
\hline 3. & Develop network of community of thought leaders who can provide support and innovative ideas. \\
\hline 4. & Develop a toolkit focused on strengthening health systems during an outbreak, with focus on health systems performance. \\
\hline 5. & $\begin{array}{l}\text { Cadre of health professionals with expertise in health systems strengthening and outbreak response to integrate the activities } \\
\text { should be developed. }\end{array}$ \\
\hline 6. & $\begin{array}{l}\text { Conduct operational and implementation research. This is to understand which interventions, strategies, and tools provide } \\
\text { the best outcomes. }\end{array}$ \\
\hline 7. & Adjust already existing health systems experts to provide guidance for outbreak response settings. \\
\hline 8. & Include funds for health systems strengthening in outbreak response budgets. \\
\hline 9. & Target communication and advocacy efforts to appeal to political leaders and affected communities. \\
\hline 10. & Align the outbreak response with health systems strengthening to ensure sustainability of efforts. \\
\hline
\end{tabular}

disease that are likely in the post covid era. Building resilient and responsive health systems is an imperative and the present epidemic is an important opportunity to address health systems strengthening. Durski et $\mathrm{al}^{8}$ have identified 10 activities that could be implemented during health emergencies to develop resilient health systems (Table 2). I believe that health system strengthening in India should be done at two levels: modification of primary healthcare and creation of better secondary health care centres.

\section{Strengthening primary healthcare}

Primary healthcare in India is currently focused on maternal and child health and communicable diseases, especially preventable hygiene-related and vaccine related diseases. In some states, the primary health system also provides care for non-communicable disease prevention and management. Most of these facilities are in rural areas and in less developed states is still in primitive stages with perennial staff and space shortages. Urban areas of the country lack a robust primary care system. The situation has not changed for decades despite exponential growth in population. A multipronged approach is required to create a resilient primary care infrastructure that is responsive to communicable diseases and non-communicable disease epidemics in both rural and urban areas. The strategies include provision of:

- Developing well equipped healthcare infrastructure to provide optimal healthcare services with first-class hygienic and well ventilated buildings, state-of-the- art medical and other equipment to fulfill all emergencies with suitable back-up support;

- Well-trained, well-paid, and adequate staff of paramedics, nurses, and physicians at primary care;

- Creation of physical infrastructure in rural, semiurban, and urban locations to provide social and economic needs of families of the medical staff;

- Supply chain logistics to ensure continuous replacement of consumables, pharmaceuticals, and staff;

- Periodic training of staff in prevention strategies for communicable diseases, monitoring non-communicable disease risk factors, and encouraging adherence to evidence-based healthy lifestyles and pharmacotherapies;

- Technology has a huge role in disease surveillance, monitoring of healthcare workers and managing logistics. However, trained manpower is crucial to maintain all the facilities.

We proposed a simple algorithm for population level surveillance and implementation of the strategies mentioned above some years ago (Figure). ${ }^{9}$ This individual and family focused algorithm not only focuses on healthcare capacity strengthening and capabilities but also on administrative pathways for successful outcome.

\section{District hospitals and secondary healthcare}

A weak link in most of the developing countries is poor status of the district hospitals. ${ }^{10}$ Rural sub-centres which 


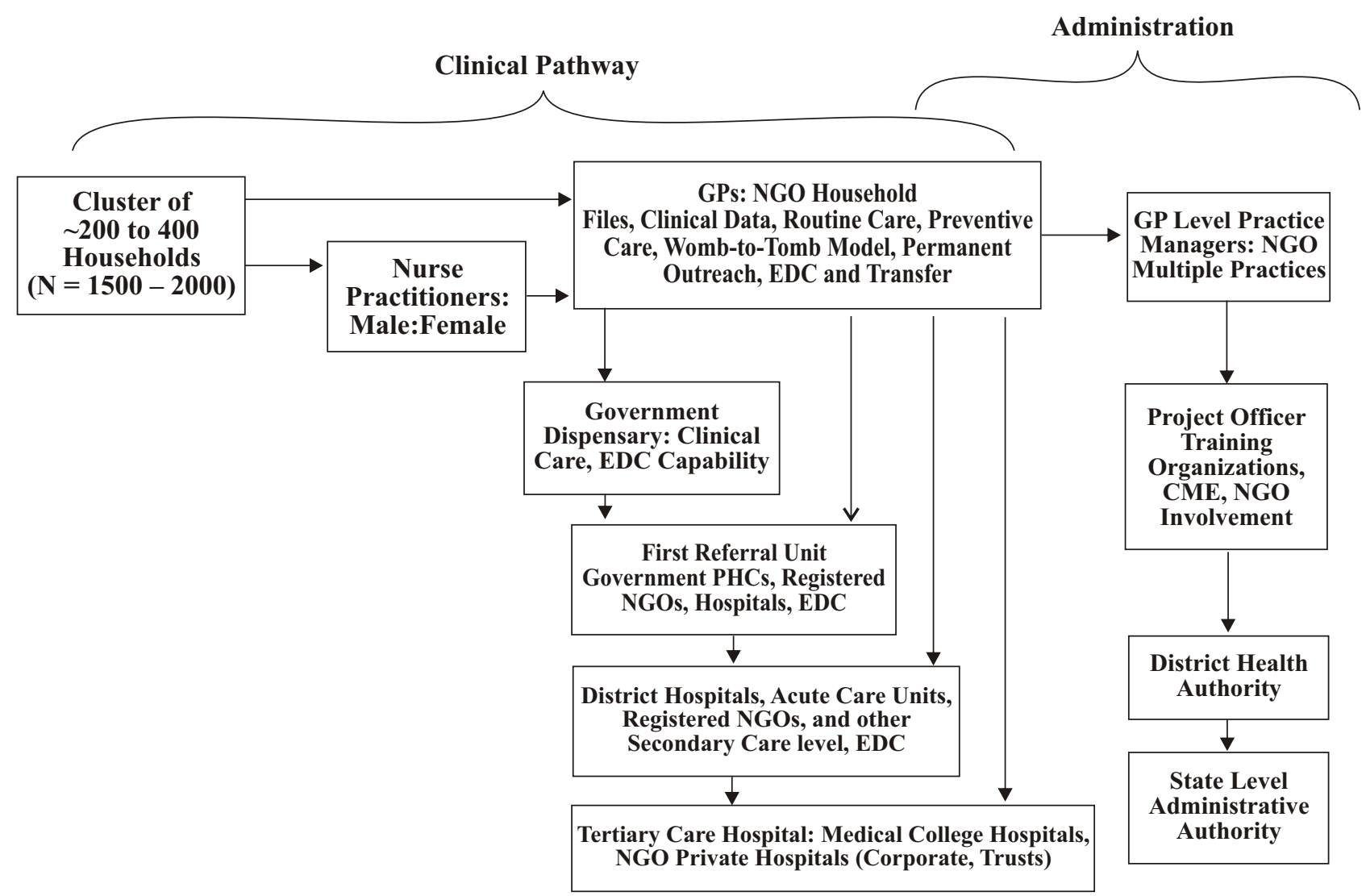

Figure: Suggested algorithm for creation of a resilient health system at primary care level in India.

EDC: electronic data capture; GP: general practitioners; NGO: non-governmental organizations; PHC: primary health centres

were initiated with Bhore Commission report of preindependence era have not been upgraded for long in most of the states of India. In 1960's and 1970's many district hospitals in the country including in our state of Rajasthan were centres of excellence in many surgical and medical specialties. ${ }^{11}$ Advances of healthcare technology and manpower specialization have left most of these hospitals behind and many of such hospitals (mainly non-government) have closed down. Most district hospitals are located at a central location in each district of India and can be a hub of medical referrals, training of health workers- including community health workers and nurses, supervision of peripheral facilities as well as public health surveillance. ${ }^{10}$ Most of these hospitals are generally 50 to 200 bed institutions that provide care for a district's 100,000 to 10 million in each district $(\mathrm{N}>600)$ and state $(n=33)$ of the country.

According to the WHO, district hospitals should offer primary health care, emergency obstetric care, general surgery, orthopedic surgery, advanced medical specialty care including basic critical care, laboratory services, and diagnostic imaging. ${ }^{10}$ In context of emerging epidemics of communicable diseases, e.g., covid-19, and non-communicable diseases these hospitals should also provide acute pulmonary and cardiovascular care including respiratory ventilator support and cardiovascular procedures. ${ }^{12}$

Creation of such a system with adequate manpower and continuously available facilities is crucial and should be an important component of post-covid-19 strategy. We have to realize that the global health landscape has expanded to encompass broader aspects of hospital-based care. Investments should be made to create highly functional district hospitals so that these systems can make progress toward integrating diverse agendas. I would like to include both government and non-government teaching and nonteaching hospitals in this category including tertiary care medical colleges. Creation of centres-of-excellence is important to provide first class preventive and curative health services to all individuals in India irrespective of social and economic class. Instead of lamenting lack of funds (to create such centres) and by denigrating world 
class non-government hospitals (many of which have set examples of excellence in healthcare delivery) we should be focusing on creating such centres within government sector. Indeed, in advanced economies of Europe there is no difference in quality of hospitals and excellence of care in government and non-government hospitals. It is a strong belief among most healthcare professionals that every Indian deserves the first class care at first class hospitals. In post-covid-19 scenario, it is expected that there would be no shortage of funds to create such centres. The following interventions are suggested to create well-managed district hospitals in government and non-government sectors:

- Building of existing hospitals should be developed anew after proper designing and focus on infrastructure that is world class, long lasting and replenishable. Instead of focusing on lowest costs we should focus on minimum basic quality to provide safe healthcare.

- Availability of well trained and dedicated staff is the main hindrance in creation of district level facilities. Such staff is not only attracted by quality of work but also with adequate promotion avenue and the overall milieu of the hospital. Social facilities and healthy living and schooling are also crucial incentives.

- Periodic upgrade of facilities and creation of subspecialties in various medical and surgical departments is important to sustain public confidence in the district hospitals.

- Training and continuous learning process are important. Every district hospital should be a hub for training of not only paramedics and nurses but also physicians.

- Supply-chain logistics are important to maintain quality of care. This is one of the weakest links.

- Technological support is important as highlighted in the figure. It has been argued that post-covid-19 scenario would spawn technologies such as cloud computing, big data analytics, artificial intelligence, internet-of-things, blockchain technologies, and robotics. ${ }^{13}$ These technologies coupled with cyber security could play an important role in healthcare of the future and can be the most important employment generator of future decades.
I believe that district hospitals should be recognized as a crucial piece in the post-covid-19 health care puzzle and important component of a resilient health system, serving both as a platform for treatment programs for various diseases and as the hub of a robust referral network for physicians, nurses, and community health workers at lower-level facilities. Increased investment in hospitalbased care is a necessary and cost-effective step toward advancing universal health coverage and strengthening health systems in India. The improvement of district hospitals is a prerequisite for any advancement of the global post-covid-19 agendas for communicable and noncommunicable diseases, surgery, and quality of care.

\section{CONCLUSIONS}

Covid-19 epidemic provides us with unique opportunities to create a resilient and strong health system that is responsive to health needs of public with focus on both communicable and non-communicable diseases. This dual epidemic is widespread in the country. ${ }^{14}$ The covid-19 epidemic has shown us that to provide excellence in health care to our population we need to strengthen primary health care in both rural as well as urban locations. Epidemiology has informed us that the countries with a robust primary health care as in Europe, Australasia, East Asia, and Kerala have rapidly reversed the course of the epidemic. On the other hand, in countries with a weak primary health system such as BRIMUS (Brazil, Russia, India, Mexico, and US), the epidemic is still raging. Strategies to strengthen primary healthcare are outlined above. Excellence in secondary healthcare is crucial and we believe that wellplaced, well-funded, well-staffed, and well-equipped district hospital should be developed as the most important component of healthcare chain in post covid-19 era. As covid-19 management involves not only evidence based communicable disease management but also involves focus on advanced respiratory, cardiovascular, and neurological care, a high class district hospital should be developed as priority. Such centres can be developed using strategies mentioned above and shall be able to provide sustainable healthcare for generations of patients with both communicable as well as non-communicable diseases.

\section{REFERENCES}

1. Gupta R, Dhamija RK, Gaur K. Epidemiological transition 
of covid-19 in India from higher to lower HDI states and territories: Implications for prevention and control. medRxiv preprints. 2020;10.1101/2020.05.05.20092593.

2. Mullard A. Covid-19 vaccine development pipeline gears up. Lancet. 2020; 395:1751-52.

3. Sanders JM, Monogue ML, Jodlowski TZ, Cutrell JB. Pharmacological treatments for coronavirus disease 2019 (Covid-19) a review. JAMA. 2020; 323:1824-36.

4. Hick JL, Biddinger PD. Novel coronavirus and old lessons: preparing the health system for the pandemic. NEngl JMed. 2020; 382:e55.

5. Chu DK, Akl EA, Duda S, Solo K, Yaacoub S, Schunemann $\mathrm{H}$, on behalf of the Covid-19 Systematic Urgent Review Group Effort (SURGE) study authors. Physical distancing, face masks and eye protection to prevent person-to-person transmission of SARS-CoV-2 and Covid-19: A systematic review and meta-analysis. Lancet. 2020; EPub.

6. Hallewell J, Abbott S, Gimma A, Bosse NI, Jarvis CI, Russel TW et al. Feasibility of controlling covid-19 outbreaks by isolation of cases and contacts. Lancet Glob Health. 2020. 8:e488-96.

7. Cash R, Patel V. Has covid-19 subverted global health? Lancet. 2020; 395:1687-88.
8. Durski KN, Osterholm M, Majumdar SS, Niles E, Bausch DG, Atun R. Shifting the paradigm: Using disease outbreaks to build resilient health systems. BMJ Glob Health. 2020;5: e002499.

9. Gupta R, Kumar P. Global diabetes landscape: Type 2 diabetes mellitus in south Asia: Epidemiology, risk factors and control. Insulin. 2008; 3:78-94.

10. Rajbhandari R, McMahon DE, Rhatigan JJ, Farmer PE. The neglected hospital- the district hospital's central role in global health care delivery. N Engl J Med. 2020; 382:397400.

11. Gupta R. Histories of healthcare in Jaipur. RUHS J Health Sciences. 2019; 4:5-10.

12. Phua J, Weng L, Ling L, Egi M, Lim CM, Divatia JV et al. Intensive care management of coronavirus disease 2019 (Covid-19): challenges and recommendations. Lancet Resp Med.2020; 8:506-17.

13. Singh S, Goyal M. Big bounty. Economic Times Magazine. 2020; 7-13; 8(22):4-6.

14. India State-Level Disease Burden Collaborators. Nations within a nation: variations in epidemiological transition across the states in India 1990-2016, in the Global Burden of Disease Study. Lancet. 2017; 390:2437-60. 